\title{
Segmented block copolymers based on poly(butylene terephthalate) and telechelic polyesters and polyamides of dimerized fatty acids
}

\author{
H. J. Manuel and R. J. Gaymans* \\ Department of Chemical Technology, University of Twente, PO Box 217. \\ 7500 AE Enschede, The Netherlands \\ (Received 17 July 1992; revised 1 March 1993)
}

\begin{abstract}
Segmented block copolymers (SBCs) based on poly(butylene terephthalate) (PBT) and telechelics based on dimerized fatty acids have been synthesized in the melt. The dimerized fatty acids were coupled with diols or diamines to synthesize polyesters and polyamides of low molar mass. With these telechelic polyesters and polyamides we studied the influence of the different types of blocks and the block length on thermal transitions with differential scanning calorimetry and dynamic mechanical thermal analysis. The melting behaviour was compared to an SBC based on a dimerized fatty acid $\left(M_{\mathrm{n}}=565 \mathrm{~g} \mathrm{~mol}^{-1}\right)$ and PBT. Neither the compositions of the SBCs nor the block lengths of the telechelic polyesters and polyamides seemed to be of influence on the melting behaviour. The glass transition temperatures ( $T_{\mathrm{g}}$ values) of the SBCs based on the telechelic polyester decreased, while the $T_{\mathrm{g}}$ of the SBC based on the primary polyamide increased. Higher reaction temperatures and longer reaction times increased $T_{\mathrm{g}}$, owing to transesterification reactions in the melt.
\end{abstract}

(Keywords: dimer acid; dimerized fatty acid; segmented block copolymer; poly(butylene terephthalate); telechelic poly(ester ester); thermoplastic elastomer)

\section{INTRODUCTION}

Segmented block copolymers (SBCs) are polymers that consist of different types of segments that alternate along the polymer backbone. Each segment of the polymer backbone has its own properties and transition temperatures. When flexible monomers are chosen SBCs can be synthesized with elastomeric properties. One segment must possess a low elasticity modulus and a low glass transition temperature $\left(T_{\mathrm{g}}\right)$. This segment imparts elastomeric properties to the material and, therefore, is often called the soft phase. The other segment is designed to undergo some sort of association so that it can form physical crosslinks. This segment will then impart dimensional stability to the material and, therefore, is often called the hard phase. Since the crosslinks in the material are of a physical nature, the materials with the elastomeric properties can be molten and processed by thermoplastic moulding techniques. For that reason the materials are called thermoplastic elastomers (TPEs).

An example of a commercial TPE that has been studied extensively in the literature ${ }^{1}$ is the segmented block copoly(ether ester). Commercial block copoly(ether ester)s are usually based on poly(tetramethylene oxide) (PTMO) and poly(butylene terephthalate) (PBT) as the rubbery and semi-crystalline components respectively. These materials and their modifications are known under

* To whom correspondence should be addressed many trade names such as Hytrel (Du Pont), Arnitel (AKZO) and Pelprene (Toyobo). These materials couple interesting properties such as high melting temperature $\left(T_{\mathrm{m}}\right)$, low $T_{\mathrm{g}}$, high tensile strengths and high tear strengths with ease of processing.

One of the disadvantages of PTMO in TPEs is that the ether group is prone to oxidative degradation ${ }^{2-5}$ and hydrolysis ${ }^{5}$ at elevated temperatures. These TPEs also degrade at ambient temperatures in sunlight ${ }^{6,7}$. For these reasons commercial copoly(ether ester)s are stabilized with various additives ${ }^{2-5,7-10}$.

An alternative to using polyethers in TPEs is to use saturated fatty acids. Hoeschele ${ }^{11}$ synthesized SBCs with a $\mathrm{C}_{36}$ dimerized fatty acid as the soft phase. All the properties concerning degradation stability were improved while most other properties were not influenced significantly. The properties at lower temperatures, however, showed poorer results due to the higher $T_{\mathrm{g}}$.

In an earlier article from our group, SBCs based on PBT and dimerized fatty acids with different molar masses $\left(565<M_{\mathrm{n}}<1038 \mathrm{~g} \mathrm{~mol}^{-1}\right)$ were discussed ${ }^{12}$. It was found that the $T_{\mathrm{g}}$ values of the SBCs were lower for the dimerized fatty acid with the larger molar mass $\left(1038 \mathrm{~g} \mathrm{~mol}^{-1}\right)$. The melting temperature increased concomitantly.

If $T_{\mathrm{g}}$ is influenced by the lengths of the amorphous segments, another possibility to lower $T_{\mathrm{g}}$ is through the use of telechelics based on dimerized fatty acids as the 
soft phase. The dimerized fatty acids can be coupled with diols or diamines to synthesize telechelic polyesters and polyamides respectively.

The aim of this work is therefore to study the synthesis and properties of SBCs with PBT as the hard phase and telechelics based on dimerized fatty acids as the soft phase.

\section{EXPERIMENTAL}

\section{Materials}

Dimethyl terephthalate (DMT), 1,4-butanediol (BDO), 1,6-hexanediamine (HMDA), piperazine, $N, N^{\prime}$-dimethylethylenediamine (DMEDA), $N, N^{\prime}$-dimethyl-1,6-hexanediamine (DMHDA), tetrabutyl orthotitanate (all synthetic grade) and methanol (analytical grade) were purchased from Merck, Hohenbrunn, Germany. The dimerized fatty acids were obtained from Unichema Chemie, Gouda, The Netherlands.

The properties of the dimerized fatty acids were discussed in a previous paper ${ }^{12}$. (Pripol 1008 has $36 \mathrm{C}$ atoms of which $13 \mathrm{C}$ atoms lie directly between the carboxy groups, a concentration of carboxy end groups of $3.46 \mathrm{meq} \mathrm{g}^{-1}$ and an iodine value of $3.8 \mathrm{mg} \mathrm{I}$ per $100 \mathrm{~g}$, and is composed of $0.1 \mathrm{wt} \%$ monomer, $0.5 \mathrm{wt} \%$ intermediate, $99.0 \mathrm{wt} \%$ dimer and $0.5 \mathrm{wt} \%$ trimer.) In this article another dimerized fatty acid - Pripol 1009 - is also used. This dimerized fatty acid has largely the same properties, but is a trifle less pure $(0.1 \mathrm{wt} \%$ monomer, $1.0 \mathrm{wt} \%$ intermediate, $98.5 \mathrm{wt} \%$ dimer and $0.5 \mathrm{wt} \%$ trimer) and more unsaturated (iodine value of 5.3)

Synthesis of telechelic amorphous polymers (dimerized fatty acid with diol/diamine)

Telechelic polyesters. Batches of $50 \mathrm{~g}$ of polymer were synthesized by placing dimerized fatty acid and diol in an agitated round bottomed flask fitted for distillation. A stainless steel stirrer with a paddle cut to conform with the internal radius of the flask was positioned at a few millimetres above the bottom of the flask. Agitation was started while nitrogen was led into the flask. The flask was placed in an oil bath at $160^{\circ} \mathrm{C}$, agitated for $5 \mathrm{~min}$ and then $0.1 \mathrm{wt} \%$ tetrabutyl orthotitanate was added. Water distilled from the reaction mixture as the temperature was slowly raised to $230^{\circ} \mathrm{C}$ over a period of $1 \mathrm{~h}$. The reaction mixture was agitated for another $1.5 \mathrm{~h}$ at $230^{\circ} \mathrm{C}$. The polyesters PPEB1 to PPEB5 were then allowed to cool down slowly to room temperature.

For the polyesters PPEB6 and PPEC1, however, the reaction continued under reduced pressure to get higher molar masses. For PPEC1 the reaction continued for $0.5 \mathrm{~h}$ under a reduced pressure of $15 \mathrm{mmHg}$. For PPEB6 the pressure was reduced to $0.5 \mathrm{mmHg}$ in $2 \mathrm{~h}$ and the reaction was continued for another $4 \mathrm{~h}$ under these conditions.

All telechelic polyesters were transparent, viscous liquids.

Telechelic polyamides. For the synthesis of the telechelic polyamides the same procedure as described for the polyesters was followed. In these syntheses the catalyst was $0.1 \mathrm{wt} \% \mathrm{MeOLi}$ from a solution of $0.3 \mathrm{~g} \mathrm{Li}$ in $25 \mathrm{ml} \mathrm{MeOH}$. The starting temperature of the oil bath was lower: $120^{\circ} \mathrm{C}$. The temperature was raised to $230^{\circ} \mathrm{C}$ in $2 \mathrm{~h}$ and then held at that level for $1 \mathrm{~h}$. The telechelic polyamides were then allowed to cool down slowly to room temperature.
For the polyamide PPAH1, however, the reaction continued under reduced pressure. The pressure was reduced to $0.5 \mathrm{mmHg}$ in $15 \mathrm{~min}$ and held at that level for $75 \mathrm{~min}$.

All products were transparent, yellow, viscous liquids except PPAH1 and PPAH2, which were yellow (slightly transparent) solids.

\section{Synthesis of segmented block copolymers}

The segmented block copolymers (SBCs) were synthesized with the same procedure as described for the polyesters. In these syntheses the reactants were BDO, DMT and polyester or polyamide. After heating from 160 to $230^{\circ} \mathrm{C}$ in a period of $45 \mathrm{~min}$, the pressure was reduced in $15 \mathrm{~min}$ to $0.5 \mathrm{mmHg}$ and the reaction was continued for $45 \mathrm{~min}$. For samples PPEB2/DMT to PPEB6/DMT the procedure was slightly different. They were heated from 160 to $240^{\circ} \mathrm{C}$ in a period of $1 \mathrm{~h}$, the pressure was reduced in $15 \mathrm{~min}$ to $0.5 \mathrm{mmHg}$ and the reaction was continued for $1 \mathrm{~h}$.

For two SBCs other starting materials were used. These copolymers were based on a telechelic polyester and prepolymerized PBT of low molar mass. This low-molarmass PBT was synthesized by heating DMT and BDO with $0.1 \mathrm{wt} \% \quad \mathrm{Ti}\left(\mathrm{OC}_{4} \mathrm{H}_{9}\right)_{4}$ from 180 to $230^{\circ} \mathrm{C}$ in $40 \mathrm{~min}$ and reacting at that temperature for $2 \mathrm{~h}$. With this low-molar-mass PBT the SBCs PPEB1/PBT and PPEC1/PBT were synthesized. In this reaction the materials were heated from 210 to $230^{\circ} \mathrm{C}$ in $10 \mathrm{~min}$. In another $10 \mathrm{~min}$ the pressure was reduced to $0.5 \mathrm{mmHg}$ and held at that level for $40 \mathrm{~min}$.

With the telechelic polyesters as starting material, white solid polymers were formed. With the telechelic polyamides, brown-yellow solid polymers resulted.

\section{Characterization}

End group titration. The amorphous polyesters were titrated to determine the concentration of carboxy end groups. The concentration was measured by dissolving $200 \mathrm{mg}$ product in freshly distilled benzyl alcohol followed by titration with $\mathrm{KOH}$ in tert-BuOH. Titration was carried out with a glass calomel electrode under nitrogen, to minimize oxidation of benzyl alcohol, in a titroprocessor Metron 636.

The concentration of amine end groups was determined by titration of a solution of $200 \mathrm{mg}$ material in an $80 / 20$ (v/v) phenol/water mixture with trifluoromethanesulfonic acid in tert-BuOH. Phenol was freshly distilled before use. Titration was carried out with a glass calomel electrode in a titroprocessor Metron 636.

The concentration of hydroxy end groups was determined by reaction of the material with an excess of acetic acid anhydride $(5 \mathrm{ml}$ of a solution of $25 \%$ acetic acid anhydride in pyridine) at 80 to $100^{\circ} \mathrm{C}$ for $1 \mathrm{~h}$. The excess acetic acid anhydride was titrated with a solution of $\mathrm{KOH}$ in tert-BuOH.

All chemicals (analytical grade) were purchased from Merck, Hohenbrunn, Germany.

Differential scanning calorimetry (d.s.c.). Thermal properties were measured with a Perkin-Elmer DSC-7. Samples of 4 to $8 \mathrm{mg}$ of the as-prepared copolymers were dried in vacuum at $100^{\circ} \mathrm{C}$ for $24 \mathrm{~h}$ prior to testing. D.s.c. curves were obtained with the following procedure

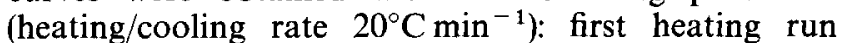
from $50^{\circ} \mathrm{C}$ to $40^{\circ} \mathrm{C}$ above the melting temperature, 
equilibration for $8 \mathrm{~min}$, and a cooling run to $50^{\circ} \mathrm{C}$; second heating run to $40^{\circ} \mathrm{C}$ above the melting temperature. The crystallization and melting temperatures were taken as the maxima in the cooling run and second heating run respectively. The crystallization and melting enthalpies were also taken from this run. The absolute error in the melting and crystallization temperatures was $\pm 2^{\circ} \mathrm{C}$. The absolute errors in the melting and crystallization enthalpies were $\pm 4 \mathrm{~J} \mathrm{~g}^{-1}$ and $\pm 2 \mathrm{~J} \mathrm{~g}^{-1}$ respectively.

Dynamic mechanical thermal analysis (d.m.t.a.). Torsion bars of approximate dimensions $80 \times 9 \times 2 \mathrm{~mm}$ were prepared by compression moulding of the as-prepared segmented block copolymers. Hereto the copolymers were placed between the heating plates of a hydraulic press (Lauffer), compressed, and kept at a temperature approximately $40^{\circ} \mathrm{C}$ above the melting temperature for $7 \mathrm{~min}$, after which cooling of the heating plates was started. The bars were subsequently dried for $18 \mathrm{~h}$ in vacuum at $100^{\circ} \mathrm{C}$. Torsion moduli were studied with a computer controlled Myrenne torsion pendulum in a temperature range from $-100^{\circ} \mathrm{C}$ to the onset of melting at a heating rate of $1^{\circ} \mathrm{C} \mathrm{min}^{-1}$ and at a resonance frequency of $1 \mathrm{~Hz}$. The maximum of the loss modulus was taken as the glass transition temperature $T_{\mathrm{g}}$. The absolute error in $T_{\mathrm{g}}$ was $\pm 2{ }^{\circ} \mathrm{C}$. The relative error in the moduli was $\pm 5 \%$.

The $T_{\mathrm{g}}$ values of the telechelic amorphous polymers were determined by an indirect route. First a piece of cloth with the right dimensions was cut. The piece of cloth was then impregnated with the polymer and dried at $40^{\circ} \mathrm{C}$ for $5 \mathrm{~h}$. The specimens were tested under the same conditions as described above.

\section{RESULTS AND DISCUSSION}

Telechelic amorphous polyesters and polyamides

Molar masses. In Table 1 the molar masses determined from calculation and end group concentrations are given.
The telechelic polyesters were prepared with an excess of dimerized fatty acid but despite this excess in acid some diol distils from the flask during the polymerization. The hydroxyl concentrations of these esters were low. The lower molar masses of the telechelic esters than aimed at is thus due to loss of diol during the reaction.

The telechelic polyamides were synthesized with an excess of diamine. Excess diamine was used to give amide groups in the coupling to the PBT segment.

Glass transition temperatures. In Table $l$ the glass transition temperatures $\left(T_{\mathrm{g}}\right)$ as measured by d.m.t.a. on the telechelic amorphous polyesters and polyamides are collected.

$T_{\mathrm{g}}$ is a function of the structure of the repeating monomer units. The $T_{\mathrm{g}}$ values of the polyesters are lower than those of the polyamides. The $T_{\mathrm{g}}$ values of the secondary polyamides lie between those of the polyesters and the primary polyamides.

The $T_{\mathrm{g}}$ of the primary polyamide $\mathrm{PPAH} 2$ is high because hydrogen bonds can be formed in the material.

The $T_{\mathrm{g}}$ values of SBCs will depend in part on the structure of the soft blocks. It is to be expected that the $T_{\mathrm{g}}$ will be lower if a soft block with a lower $T_{\mathrm{g}}$ is used. SBCs based on the telechelic polyesters are therefore the most promising materials. They were synthesized as well as a few SBCs based on the telechelic secondary polyamides.

\section{Segmented block copolymers}

Differential scanning calorimetry. D.s.c. data for the dried copolymers are collected in Table 2 . From this table several conclusions can be drawn.

The melting temperatures are, within experimental error, equal for all samples (that have the same weight fraction of PBT: $60 \%$ ). The use of PBT instead of DMT/BDO as the starting material for the SBC hard segment does not seem to influence $T_{\mathrm{m}}$ (or the other d.s.c. data). Also, the melting temperature is not influenced by

Table 1 Calculated and experimental molar masses and glass transition temperatures of the synthesized low-molar-mass polyesters/polyamides

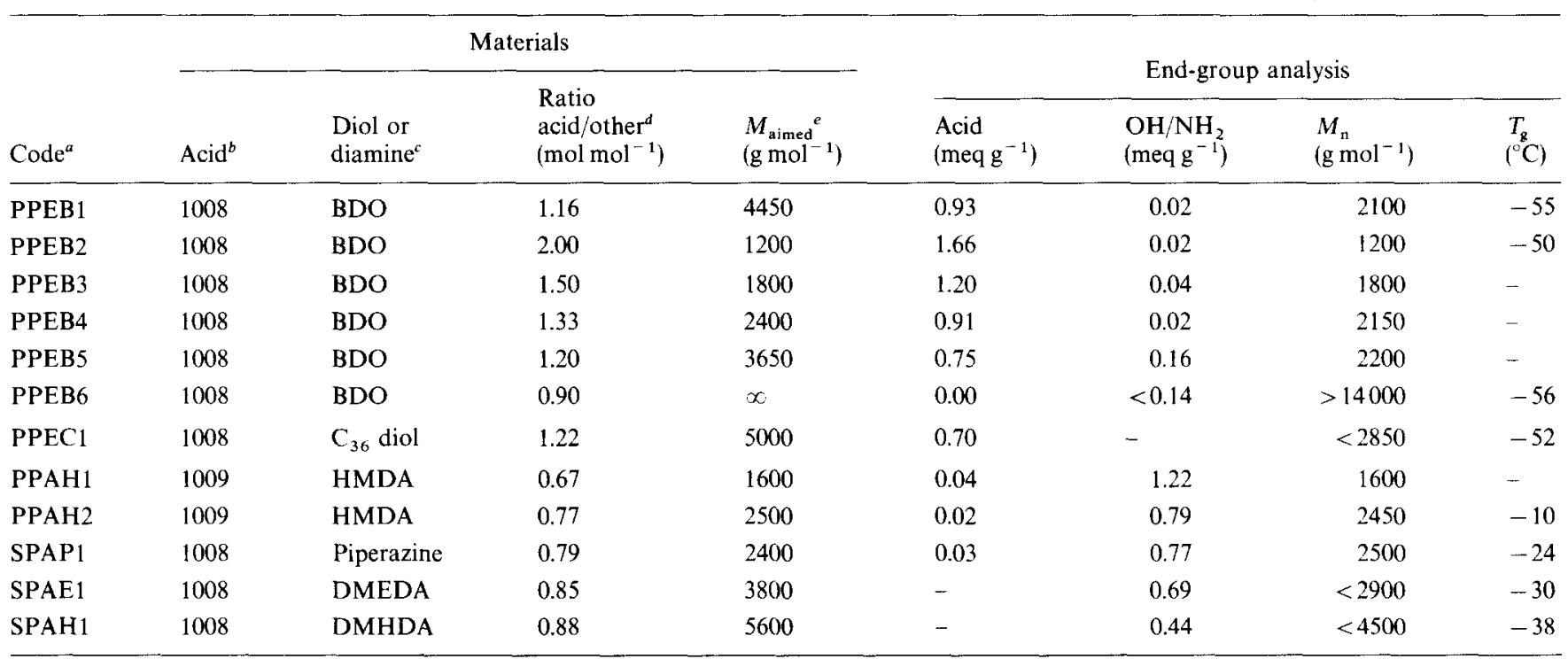

${ }^{a}$ Notation: first letter Primary or Secondary; second and third letters PolyEster or PolyAmide; fourth letter denotes the diol/diamine used

${ }^{b}$ Pripol 1008 and 1009 from Unichema Chemie were used

${ }^{c} \mathrm{BDO}=1,4$-butanediol; $\mathrm{C}_{36}$ diol = dimerized fatty acid diol based on Pripol 1009; HMDA =1,6-hexanediamine; DMEDA =N,N'-dimethylethylenediamine; DMHDA $=N, N^{\prime}$-dimethyl-1,6-hexanediamine

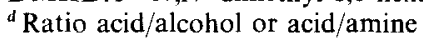

${ }^{e} M_{\text {aimed }}=M$ calculated from the ratio of reactants 
Table 2 D.s.c. data and torsional data of SBCs based on low-molarmass amorphous polyesters/polyamides and DMT or PBT

\begin{tabular}{lccccccc}
\hline Code $^{a}$ & $\begin{array}{c}T_{\mathrm{m}} \\
\left({ }^{\circ} \mathrm{C}\right)\end{array}$ & $\begin{array}{c}T_{\mathrm{c}} \\
\left({ }^{\circ} \mathrm{C}\right)\end{array}$ & $\begin{array}{l}\Delta T \\
\left({ }^{\circ} \mathrm{C}\right)\end{array}$ & $\begin{array}{l}\Delta H_{\mathrm{m}} \\
\left(\mathrm{Jg}^{-1}\right)\end{array}$ & $\begin{array}{l}-\Delta H_{\mathrm{c}} \\
\left(\mathrm{Jg}^{-1}\right)\end{array}$ & $\begin{array}{l}T_{\mathrm{g}} \\
\left({ }^{\circ} \mathrm{C}\right)\end{array}$ & $\begin{array}{l}G_{20}^{\prime} \mathrm{C} \\
(\mathrm{MPa})\end{array}$ \\
\hline $1008 \mathrm{H} 60$ & 185 & 146 & 45 & 21 & 32 & -26 & 60 \\
PPEB1/DMT & 185 & 144 & 41 & 27 & 16 & -35 & 54 \\
PPEB1/PBT & 176 & 137 & 39 & 21 & 22 & -35 & 63 \\
PPEB2/DMT & $-{ }^{b}$ & 126 & - & - & 28 & -31 & 58 \\
PPEB3/DMT & $-b$ & 142 & - & - & 27 & -31 & 50 \\
PPEB4/DMT & 185 & 135 & 50 & 13 & 29 & -31 & 63 \\
PPEB5/DMT & 184 & 148 & 37 & 22 & 26 & -31 & 60 \\
PPEB6/DMT & 186 & 140 & 46 & 24 & 29 & -28 & 55 \\
PPEC1/DMT & 184 & 133 & 51 & 24 & 28 & -27 & 50 \\
PPEC1/PBT & 180 & 129 & 51 & 21 & 25 & -33 & 50 \\
PPAH1/DMT & 170 & 130 & 40 & 21 & 19 & -6 & 92 \\
PPAH2/DMT & 186 & 142 & 44 & 33 & 18 & 10 & 85
\end{tabular}

${ }^{a} 1008 \mathrm{H} 60$ is an SBC based on Pripol $1008\left(M_{n}=565 \mathrm{~g} \mathrm{~mol}^{-1}\right)$ and DMT/BDO; PPEB1/DMT is an SBC based on PPEB1 as the soft phase and DMT/BDO as the hard phase. PBT was of low molar mass and used as the hard phase

${ }^{b}$ No melting peaks could be detected

the molar mass of the amorphous polymer used. This can be seen by comparing $1008 \mathrm{H} 60$ (based on unpolymerized dimerized fatty acid, $M_{\mathrm{n}}=565 \mathrm{~g} \mathrm{~mol}^{-1}$ ) with the other materials (with increased $M_{\mathrm{n}}$ ). The melting temperature was expected to increase with increasing molar mass of the amorphous polymer, because this also would increase the block length of the hard PBT segments.

The crystallization temperature, $\Delta H_{\mathrm{m}}$ and $\Delta H_{\mathrm{c}}$ behave analogously to $T_{m}$, although the errors in these data are somewhat larger than for $T_{\mathrm{m}}$. In an earlier paper ${ }^{12}$ it was shown that the enthalpy is influenced by composition only.

The use of telechelic polyamide compared to the use of telechelic polyester does not seem to have any influence on the melting behaviour.

Dynamical mechanical thermal analysis. D.m.t.a. data for the compression moulded samples are also collected in Table 2.

From the table it can be concluded that $T_{\mathrm{g}}$ is influenced by the length and type of soft block. Increasing the length of the soft block from $565 \mathrm{~g} \mathrm{~mol}^{-1}$ (Pripol 1008 alone) to around $2000 \mathrm{~g} \mathrm{~mol}^{-1}$ (amorphous polyester PPEB1) results in a decrease in $T_{\mathrm{g}}$ of $10^{\circ} \mathrm{C}$. When polyamides are used the glass transition temperature is increased considerably, as was expected. The moduli of these polyamide based materials are also increased significantly.

Employment of polyester PPEC1 does not seem to give an advantage over the use of telechelic polyesters from $\mathrm{BDO}$ with dimerized fatty acid (PPEB). The use of PBT instead of DMT/BDO does not seem to influence $T_{\mathrm{g}}$ or the modulus. Also, for the amorphous polyesters PPEB2 to PPEB6 there seems to be no influence of the molar mass of the telechelic on $T_{\mathrm{g}}$ or

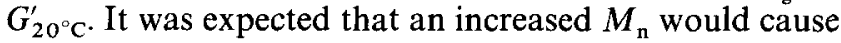
a decreased compatibility between PBT blocks and the amorphous phase such that $T_{\mathbf{g}}$ would probably decrease. The $T_{\mathrm{g}}$ values for the materials PPEB2/DMT to PPEB6/DMT are higher than that of PPEB1/DMT, although $M_{n}$ for PPEB1 is of the same order as the $M_{\mathrm{n}}$ values for PPEB4 and PPEB5. This possibly is caused by the different polymerization times. Long reaction times allow a considerable amount of transesterification to take place, leading to a decrease in the molar mass of the aliphatic polyester block.

To test the influence of the reaction conditions a few copolymers were synthesized based on PPEB4 under different conditions. In Table 3 the reaction conditions and $T_{\mathrm{g}}$ values of the corresponding materials are contained.

The table shows that the $T_{\mathrm{g}}$ is influenced by the reaction conditions. Longer reaction times and higher reaction temperatures increase $T_{\mathrm{g}}$. This effect is not quite unexpected. If the catalyst is not killed transesterification will always occur when heating polyesters to their melting temperature. From this table it is evident that the reaction conditions do influence the properties of the SBCs. Possibilities to overcome this problem are already described in the literature. AKZO, for example, produced a poly(ester ester) by reacting a hydroxy terminated PBT of low molar mass with an isocyanate terminated amorphous telechelic polyester ${ }^{13,14}$. It is also possible to couple hydroxy terminated hard and soft polyesters with diisocyanates $^{15}$. Snijder used another approach still ${ }^{16}$. He took poly(ethylene terephthalate) and a copolyester of ethylene terephthalate and ethylene sebacate, both of high molar mass. By transesterification reactions in the melt, the molar masses of both polymers decreased until a homogeneous melt was formed. This route, however, is not so suitable for commercial products because the reaction cannot be adequately controlled.

\section{CONCLUSIONS}

In this work segmented block copolymers (SBCs) based on telechelic dimerized fatty acid polymers and DMT/BDO or PBT were synthesized.

The dimerized fatty acids were first polymerized with diols or diamines to give polyesters or polyamides respectively. The $T_{\mathrm{g}}$ in the SBC decreased in the order secondary polyamides $>$ tertiary polyamides $>$ polyesters. To synthesize SBCs with low $T_{\mathrm{g}}$ values the telechelic polyesters are therefore preferred as soft building blocks.

Compared to a sample based on a dimerized fatty acid the use of a telechelic of a dimerized fatty acid does not seem to influence the melting behaviour of the SBC significantly. The glass transition temperature is increased by using primary polyamides and decreased by polyesters compared to the SBC based on a dimerized fatty acid. The use of prepolymerized PBT again shows no significant effect.

Longer reaction times and higher reaction temperatures increase $T_{\mathrm{g}}$ owing to transesterification reactions that occur in the melt.

Table 3 Reaction conditions ${ }^{a}$ used in the synthesis of SBCs based on the low-molar-mass amorphous polyester PPEB4 and the resulting $T_{\mathrm{g}}$ values

\begin{tabular}{llllll}
\hline Code & $\begin{array}{l}t_{\text {heat }} \\
(\mathrm{h})\end{array}$ & $\begin{array}{l}t_{\text {polym }} \\
(\mathrm{h})\end{array}$ & $\begin{array}{l}t_{\text {tot }} \\
(\mathrm{h})\end{array}$ & $\begin{array}{l}T_{\max } \\
\left({ }^{\circ} \mathrm{C}\right)\end{array}$ & $\begin{array}{c}T_{\mathrm{g}} \\
\left({ }^{\circ} \mathrm{C}\right)\end{array}$ \\
\hline PPEB4/A & 0.92 & 0.92 & 1.84 & 220 & -36 \\
PPEB4/B & 0.75 & 1.50 & 2.25 & 230 & -32 \\
PPEB4/C & 1.00 & 1.25 & 2.25 & 240 & -31 \\
PPEB4/D & 1.50 & 1.75 & 3.25 & 240 & -24 \\
\hline
\end{tabular}

${ }^{a} t_{\text {heat }}=$ warming-up time; $t_{\text {polym }}=$ polymerization time; $t_{\mathrm{tot}}=$ total time of heating up and polymerization; $T_{\max }=$ maximum temperature used 


\section{ACKNOWLEDGEMENTS}

This work is part of the research programme of the University of Twente and was supported financially by Unichema Chemie, Gouda, The Netherlands. The authors wish to thank A. J. M. Heijnen, E. K. Poels and H. G. Stigter from Unichema for their active interest in the project.

\section{REFERENCES}

1 Adams, R. K. and Hoeschele, G. K. in "Thermoplastic Elastomers' (Eds N. R. Legge, G. Holden and H. E. Schroeder), Hanser, Munich, 1987 , Ch. 8

2 Hoeschele, G. K. Angew. Makromol. Chem. 1977, 58/59, 299
Zeilstra, J. J. Angew. Makromol. Chem. 1985, 137, 83 Hoeschele, G. K. US Pat. 38960781975

Brown, M., Hoeschele, G. K. and Witsiepe, W. K. US Pat. 3835098 1974

6 Lemaire, J., Arnaud, R. and Gardette, J. Pure Appl. Chem. 1983, 55, 1603

7 Hoeschele, G. K. US Pat. 41850031980 Hoeschele, G. K. US Pat. 38567491974 Hoeschele, G. K. US Pat. 39047061975 Hoeschele, G. K. US Pat. 42217031980 Hoeschele, G. K. US Pat. 39546891976 Manuel, H. J. and Gaymans, R. J. Polymer 1993, 34, 635

13 Van Berkel, R. W. M., De Graaf, S. A. G., Huntjens, F. J. and Vrouenrates, C. M. F. in Developments in Block Copolymers - I' (Ed. I. Goodman), Applied Science, London, 1982, p. 261

14 Huntjens, F. J. Eur. Pat. 1346/ 1983

15 Huntjens, F. J. and Brouwer, A. H. J. US Pat. 44839701984

16 Snijder, M. D. US Pat. 26230311952 